\title{
Leadership and innovation: The moderator role of organization support for innovative behaviors
}

\author{
Mozhdeh Mokhber, Wan Khairuzzaman and Amin Vakilbashi
}

\begin{abstract}
This study aims to advance the understanding of direct and moderated effect of transformational leadership on organizational innovation. A new framework is proposed in this research to identify the moderating effect of organization support for idea generating, risk taking and decision-making on the relationship between transformational leadership and organizational innovation. A sample of 63 companies from top 100 Iranian companies participated in this research. The results of this study supported the expected positive relationship between transformational leadership and organizational innovation. Besides, two of the predicted moderating effects were supported in this research. The results suggest that transformational leaders might not only promote innovative activity within the organization but also ensure the market success of the innovations.
\end{abstract}

Keywords: transformational leadership, organizational innovation, support for innovative behaviors, partial least squares (PLS) analysis

Received 11 January 2015. Accepted 19 April 2017

\section{INTRODUCTION}

This study tries to expand the understanding of transformational leadership's effect on organiza1 tional innovation. This topic is important because almost all organizations are facing a dynamic environment, rapid changes in technologies and a high demand for new products and services. For moving through growth and survival, companies must develop new and inimitable approaches to attract and save their customers. Whether the organization is doing a business or providing a service to the customer's life, creativity and innovation can be a good solution to become flexible while encountering business environment changes. As innovation can play an effective role in economic growth and development, it needs to be fostered both individually and in organizational level (Jung, Chow, \& Wu, 2003).

Over the past years, research on organizational innovation antecedents attempts to identify the factors that enhance and facilitate organizational innovation. As a result, some researchers investigated the importance of leadership in relation with organizational innovation and identified related factors such as leader's behaviors or characteristics that significantly affect organizational innovation (Shin, 1996; Jung, Chow, \& Wu, 2003; Gumusluoglu \& Ilsev, 2009b; Makri \& Scandura, 2010). Previous studies revealed that leadership with its dominant role in the organization is one of the key factors that affect organizational innovation (Jung, Chow, \& Wu, 2008). Leaders can guide organizations toward

\footnotetext{
International Business School (IBS), Universiti Teknologi Malaysia, Kuala Lumpur, Malaysia

Corresponding author: mozhdeh@ibs.utm.my
} 
becoming more innovative through their actions. Leaders initiate and implement changes that help a firm pursue organizational innovation more effectively. Leadership is a central position to support innovation by influencing firm strategic decisions, policies and procedures, and they are key agents for promoting changes in the firm that support innovation (Prasad \& Junni, 2016).

Besides the importance of leadership for organizational innovation, the paramount importance is having the right type of leadership to effectively drive innovation in the organization (Oke, Munshi, \& Walumbwa, 2009). Among a wide range of research on leadership, a set of adoptive leadership behaviors labeled 'transformational' held to be more effective in enhancing organizational innovation than other leadership styles (Jung, Chow, \& Wu, 2003, 2008; Bass \& Riggio, 2006; Sarros, Cooper, \& Santora, 2008; Gumusluoglu \& Ilsev, 2009a; Hsiao, Chang, \& Tu, 2009). Theoretical and empirical studies have found that transformational leaders are more capable in supporting values and norms of followers and foster organizational and personal changes (Jung, Chow, \& Wu, 2003). Transformational leaders are able to support organizational innovation by enhancing the motivation and ability of organizational members to be creative and innovative. Transformational leaders develop enthusiasm among organizational members to think out-of-the-box and be more creative and to develop new ideas and solutions concerning organizational structures, processes and practices (Prasad \& Junni, 2016). Feng, Huang, and Zhang (2016: 857) believe that 'transformational leadership is a necessary leadership practice that can keep pace with the changing times and improve an enterprise's innovative capacity.'

Previous researchers believed that in spite of agreement on the importance of leadership for innovation, little research has been done on the nature of this link (Mumford, 2002; García-Morales, Matías-Reche, \& Hurtado-Torres, 2008; Jung, Chow, \& Wu, 2008; Gumusluoglu \& Ilsev, 2009a; Hsiao, Chang, \& Tu, 2009; Oke, Munshi, \& Walumbwa, 2009; Makri \& Scandura, 2010). It has been argued that previous studies in the field of innovation and leadership are not sufficiently benefited by each other and mostly studied in separate areas (Imran \& Anis-ul-Haque, 2011; Feng, Huang, \& Zhang, 2016; Prasad \& Junni, 2016).

This study elaborates the influence of transformational leadership on organizational innovation at the level of organizations. 'Being held to be a key driver of innovation at the organizational level, transformational leadership's effects have mostly been studied at the levels of individual employees or organizational subunits (Jung, Chow, \& Wu, 2008: 582). The problem with such a focus is that, unless the innovative behaviors and individuals' production and subunits are consonant to produce organizational-level outcomes, the organization as a whole still is left without a proper response to the challenges of a competitive market environment (Jung, Chow, \& Wu, 2008). Moreover, previous studies suggest that transformational leadership has a stronger correlation with innovation at the organizational level than at the individual level of analysis (Rosing, Frese, \& Bausch, 2011). Therefore extending a research to this level of analysis has a good contribution to knowledge and more systematic understanding of the relationship between transformational leadership and innovation in the organization is not only timely but even essential (Jong \& Hartog, 2007).

Beside the need for more empirical research to support the theoretical propositions on the relationship between transformational leadership and organizational innovation, the inclusion of mediators or moderators as intervening variables on this link has yet to be examined comprehensively (Jaskyte, 2004; Jung, Chow, \& Wu, 2008; Gumusluoglu \& Ilsev, 2009a; Khan, Rehman, \& Fatima, 2009; Makri \& Scandura, 2010). Findings of previous studies suggest that more research is required to clearly focus on the link between transformational leadership and innovation as well as the conditions that constrain this relationship. According to Rosing, Frese, and Bausch (2011), the results of previous studies on leadership and innovation do not lead to a simple conclusion and they arrive at different results. Although different leadership styles are positively related to innovation, but most of them show a broad range of correlations that depend on moderating conditions. The variation of the results suggests that the relationship between transformational leadership and innovation depends on other 
variables, such as level of analysis, source of innovativeness rating as well as several features of the organizations studied (e.g., climate for excellence, support for innovation, etc.). Previous studies have argued that the relationship between transformational leadership and organizational innovation was not always same, which calls for exploring mediating and moderating factors between them (Choi, Kim, Ullah, \& Kang, 2016).

Findings of previous studies imply that a leader with transformational leadership style needs to focus on different aspects of the innovation process, such as an overall supporting environment to complement his/her influences. This supporting environment is considered as the supportive contribution of an organization to its employees to increase satisfaction and improve the performance. Therefore it can encourage the employees to be fully devoted to innovation activities by supporting mechanisms in the organization (Choi et al., 2016). Although many organizations use different types of stimulating factors to promote organizational innovation, organization's support for innovative behavior is an important factor to mobilize the innovation process (Martins \& Terblanche, 2003). Innovative behaviors result in new idea generation and thinking of new ways of doing work must be nurtured by leaders in order to give the organization a chance to produce innovative outcomes (Amabile, 1998).

It has been argued that innovative behaviors are the basis of organizational change and fundamental to organizational innovation (Tsai \& Tseng, 2010). Based on the findings of previous studies, organizations that are open to change, supportive of idea generation and allow the employees to think about problems in different ways, are revealing behaviors that encourage innovation (Jung, Chow, \& Wu, 2003; Martins \& Terblanche, 2003; Gumusluoglu \& Ilsev, 2009a; Poppendick, 2009). Therefore a further advance over previous studies is that this research introduces organization support for innovative behaviors, which may interact with transformational leadership behaviors in affecting organizational innovation. Review of literature indicated that support for innovative behaviors as an innovation climate in the organization received only limited attention as a moderator (Gumusluoglu \& Ilsev, 2009a).

Jung, Chow, and Wu (2003) found that transformational leadership has a significant positive relationship with organizational innovation directly and indirectly through organization's extent of employee empowerment and climate for innovation. They emphasized that it is necessary to expand and refine the measurement of organizational innovation because the proxies that they employed to measure organizational innovation, only reflect the organization's willingness to support innovation rather than the success of organization in generating outcomes. Also, Gumusluoglu and Ilsev (2009a) identified that followers' creativity mediates the relationship of transformational leadership and organizational innovation. They focused on mediating effect of intrinsic motivation, psychological empowerment and perception of support for innovation on the relationship of transformational leadership and followers' creativity. They tested this model among 163 R\&D personnel and managers in 43 micro and small-sized Turkish entrepreneurial software development companies and employed hierarchical regression analyses to test the hypothesis. Gumusluoglu and Ilsev (2009a) did emphasize on the need for future research in this area due to some limitations in their study, including a small sample compromised of males, focusing on a single industry, considering only small-sized companies and the necessity of longitudinal study in a real work setting which might be the possibilities of future research.

Although literature review on the relationship between transformational leadership and innovation suggests that transformational leadership correlates positively with innovation; however, there is a high degree of variation in the results.

Therefore present study is a step on the way to develop a framework that provides better understanding of the link between transformational leadership and organizational innovation and advances over previous studies in several ways. First, despite difficulties and complexities of obtaining a large 
sample in studying issues at the organizational level, the sample of this research includes larger number of firms comparing with previous studies (Jung, Chow, \& Wu, 2003, 32 companies and Jung, Chow, $\& \mathrm{Wu}, 2008,50$ companies). Also, the sample of this study covered the large-sized companies in both manufacturing and service sector in 14 different industries. Second, as the perception of employees from their top managers' leadership style supplied the survey data, and different employees may have different perceptions, in every organization more than one respondent participated in this study which may lead to more powerful hypothesis tests in this level of analysis. Third, as mentioned earlier, the variation found in the relationship between leadership and innovation could also be due to methodological or statistical reasons. Therefore more attention was devoted in this research to expand the measurement of organizational innovation which was a limitation of previous studies. Moreover, this study considered structural equation modeling-partial least squares (PLS) to bridge the methodological gaps as well as enhancing the statistical analysis. Fourth, this study elaborates the influence of certain types of transformational leadership behaviors developed by Bass (1985) (i.e., idealized influence, attributed charisma, inspirational motivation, intellectual stimulation and individualized consideration) on organizational innovation. Finally, this research proposes moderating effects of organization support for innovative behaviors including idea generating, risk taking and decision-making on the link between transformational leadership and organizational innovation. The following section explains the theoretical basis for the direct and moderated hypothesized effects in this study.

\section{THEORETICAL BACKGROUND AND HYPOTHESES}

\section{The effect of transformational leadership on organizational innovation}

According to Slappendel (1996) and Hage (1998) much of the early literature on innovation concentrated at the individual level and addressed the adoption of new ideas and practices by individuals. Since 1980s studies were conducted to identify how organizations adopt innovations and examined the relationship between specific organizational variables and organizational innovativeness. In a general sense, the term 'organizational innovation' refers to the creation or adoption of an idea or behavior new to the organization (Daft, 1978; Damanpour \& Evan, 1984; Damanpour, 1996). Given the importance of innovation as a necessity for effectiveness, revolution, survival and competitiveness of the organizations (Woodman, Sawyer, \& Griffin, 1993), several studies have persuaded to identify factors that enhance and facilitate organizational innovation. The review of relevant literature indicated that leadership has been identified as one of the most important factors influencing organizational innovation (Jung, Chow, \& Wu, 2008). Organizations are greatly influenced by their leaders and research findings supported that some factors related to leadership such as leadership behaviors or characteristics, significantly affect organizational innovation (Jung, Chow, \& Wu, 2003; Gumusluoglu \& Ilsev, 2009a; Makri \& Scandura, 2010). Among a wide range of research on leadership styles, transformational leadership is a specific promising focus of leadership and innovation studies (Jung, Chow, \& Wu, 2003). Transformational leadership can be related to organizational innovation through several features including interactive vision, effective communication and providing an environment to support innovative teams. Bass (1985) has described transformational leadership as an adaptive leadership style with five key components including idealized influence, attributed charisma, inspirational motivation, intellectual stimulation and individualized consideration. In early research, idealized influence and charisma were combined and formed a single factor but according to Bass and Riggio (2006) it makes a good sense to conceptualize them separately. Thus in this study, consistent with Bass (1985), transformational leadership is an adaptive leadership style with five key components as follows.

Idealized influence emphasizes on the leader's behavior and ability to influence the ideals and ideas of followers and even goes beyond that to influence their life matters. Transformational leaders serve as 
role models for their followers. In idealized influence, followers look for the principles and behaviors of leaders, which create trust, respect and admiration. In short, followers wish to simulate leaders with these kinds of behaviors. It seems that leaders with high levels of idealized influence are more open to risk taking and can be relied upon by followers.

Attributed charisma is one of the key components of transformational leadership that concentrates on the attribution of followers concerning the leader's behavior, which is directly related to leader's ability. The concepts of idealized influence and attributed charisma both emphasize the ability of the leader to influence the emotions and thoughts of followers when asking them to be committed in supporting the goals, mission and vision of the leader. This follower support seems to have the ability to affect the culture and performance of organizations (Conger, 1999; Avolio, 2003).

Inspirational motivation provides inspiration and contextual motivation to followers. Engaging a group of employees in optimistic behaviors, positive attitudes and continuous enthusiasm is an important goal of inspirational motivation. Through inspirational motivation, leaders attempt to present innovative ideas of doing the work for followers in order to decrease the amount of their work and show his or her commitment to them (Avolio et al., 1991).

Intellectual stimulation - through intellectual stimulation, transformational leaders stimulate followers' creativity by encouraging them to question the leaders, the organizations and their own assumptions and beliefs. Bass and Riggio (2006) noted that in this dimension of transformational leadership, leaders attempt to foster innovative approaches and provide solutions to problems by supporting followers while they are challenging and questioning assumptions and beliefs. In this process, criticism of followers due to their errors is not allowed and individuals are stimulated and feel free to suggest innovative solutions and approaches to problems, and to propose new ideas. In this way, a stimulating and innovative environment will be provided for followers and this connection between transformational leadership and innovation in the organization is one of the main objectives of this research.

Individualized consideration - transformational leaders try to act as a mentor, coach or advisor in their relationship with followers and this will provide the individual consideration. Individualized consideration focuses on ensuring and enabling followers to reach their highest and best potential and to provide opportunities in order to learn and develop their capacity (Bass \& Riggio, 2006). Individualized consideration changed the direction of considering leader's self-interest toward the follower and organization interest and ensuring development of followers by providing a challenging work environment and coaching (Bass, 1990).

In conclusion, leaders with idealized influence and charisma demonstrate loyalty to important and basic values and principles while paying more attention to followers' needs rather than their own needs. With inspirational motivation, leaders provide meaning and challenges to the work of followers. Intellectual stimulation involves followers' stimulation to resolve the problems using new approaches and the questioning of the assumptions. Finally, individualized consideration is about focusing on individual needs of followers by mentoring, coaching and providing opportunities for learning and preparing a supportive climate for growth (Jung, Chow, \& Wu, 2008; Oke, Munshi, \& Walumbwa, 2009). By means of their behavior, transformational leaders create personal and professional commitment from subordinates toward higher-level needs like self-esteem and self-actualization (Bass, 1985; Gardner \& Avolio, 1998). Sequentially, this increases the latter's inherent motivation, which has been identified as an important driver of employee creativity and organizational innovation (Oldham \& Cummings, 1996; Amabile, 1998). In order to measure the relationship between transformational leadership and organizational innovation, based on the research background and objectives of this study the following hypotheses were developed:

Hypothesis 1: Transformational leadership is positively related to organizational innovation. 


\section{Moderating effects of organization support for innovative behaviors}

It must be considered that transformational leadership behaviors occurs in the context of the organization and analyzing a bivariate relationship would be incomplete without considering the organizational context in which organizational innovation take place (Jung, Chow, \& Wu, 2008; Oke, Munshi, \& Walumbwa, 2009). Therefore it is necessary to identify and examine organizational attributes that may interact with leadership behaviors in affecting organizational innovation (Jung, Chow, \& Wu, 2003).

Being a great motivational issue, innovative behaviors has become an interest to leadership and innovation research (Pieterse, Van Knippenberg, Schippers, \& Stam, 2010). The stimulation of organizational innovation is highly depended on an organization that encourages innovation. Supporting and encouraging innovative behaviors would share a perception of the practices, procedures, policies and the ways things are done around the organization. Consequently, the organization would be perceived based on specific behavioral tendencies, attitudes and feelings (Jong \& Hartog, 2003) which might be supportive of innovation. Innovative behaviors are closely related to superiors' leadership style because leaders are the one who establish organizational goals, make decision on adopting and applying new ways of doing job and motivate employees (Tsai \& Chen, 2010). Support for innovative behaviors in the organization may provide a better communicating atmosphere for employees and leaders which ultimately contribute to organizational innovation. Review of literature indicated that support for innovative behaviors as an innovation climate in the organization received only limited attention as a moderator (Gumusluoglu \& Ilsev, 2009a). As cited in Pieterse et al. (2010) focusing on moderation is consistent with the contingency approach in leadership, which provides compelling evidence that leader effectiveness is often dependent on other factors (e.g., task context, follower characteristics; e.g., Fiedler, 1964; House et al., 1971; Yukl, 2002; van Knippenberg \& Hogg, 2003). Therefore, the presence of moderator variables could be one possible reason for the previous inconsistent results. Indeed too little is known about the impact of moderator variables on the effects of transformational leadership (Pieterse et al., 2010). Therefore this research examined the moderating effect of organization support for innovative behaviors on the relationship between transformational leadership and organizational innovation by developing the following hypothesis:

Hypothesis 2: Support for innovative behaviors moderate the relationship between transformational leadership and organizational innovation.

The model guiding this study to introduce and define innovative behaviors is developed by Martins and Martins (2002) suggesting seven determinant of organizational culture that promote innovation and creativity in the organization including strategy, purposefulness, trust relationship, behaviors that encourage innovation, working environment, customer orientation and management support. They conceptualized and explained behaviors that encourage innovation as determinants of an organization's culture that encourage innovation based on the importance of leadership and other cultural dimensions. According to Martins and Terblanche 'values and norms that encourage innovation manifest themselves in specific behavioral norms that promote or inhibit creativity and innovation' (2003: 72). Martins and Martins (2002) suggested that idea generating, risk taking and decision-making are behaviors that encourage innovation when they are accepted as a cultural norm in the organization. Jung, Chow, and Wu (2008) have provided initial evidences suggesting that supportive climate for innovation might have moderating effect on the link between transformational leadership and organizational innovation. They noted that, when there is no supportive climate for innovation in organization the transformational leaders' behavior may only slightly stimulate followers toward innovation (Jung, Chow, \& Wu, 2008). Oke, Munshi, and Walumbwa (2009) proposed that the effect of transformational leadership on innovation will be moderated by organizational contexts that 
encourage innovative behaviors and support innovative culture. This research propose that transformational leadership by the top manager can enhance organizational innovation directly and also indirectly by creating an organizational culture or climate in which employees are encouraged to freely discuss and try out innovative ideas and approaches, take risks and participate in decision-making. Therefore, in line with theoretical findings of previous studies, in this research support for idea generating, risk taking and decision-making (i.e., behaviors that encourage innovation) are considered as moderating variables in the relationship of transformational leadership and organizational innovation. In the following subsections, the expectations of how idea generating, risk taking and decisionmaking moderate the relationship between transformational leadership and organizational innovation would be developed.

\section{Idea generating}

An organization that encourages personnel to generate new ideas (Gudergan, Ringle, Wende, \& Will, 2008) and evaluates their ideas fairly (Amabile, 1998) can stimulate and encourage innovation. Usually new idea represents a change to the existing situation and comes with evaluation of the idea and the person who offered it. So it has been observed that generating and suggesting new idea is quite risky for the person who is proposing (Jong \& Hartog, 2003). Therefore, in order to stimulate innovation, it is important for organizations to be supportive of idea generating and demonstrate that new ideas can be expressed openly without being criticized or punished. Oke, Munshi, and Walumbwa (2009) proposed that the effect of transformational leadership on innovation will be higher where some organizational contexts such as facilitating idea generation are present and active rather than they are inactive or absent. To examine the moderating effect of idea generating on the link between transformational leadership and organizational the following hypothesis was developed:

Hypothesis 2a: Idea generating moderates the relationship between transformational leadership and organizational innovation.

\section{Risk taking}

Experimentation and risk taking are behaviors closely related to innovation and creativity (Martins $\&$ Terblanche, 2003). Organizations have to exhibit that risk taking and experimenting are tolerable behaviors and create values to support these kinds of behaviors. They must allow employees freedom in taking risk while increasing the possibility of success by calculating and balancing a moderate risk taking (Martins \& Martins, 2002). Several authors confirmed that creating values supportive of risk taking in the organization increase the acceptance of leader by the employees and lead to shaping the organization's level of innovativeness (Hasenfeld, 2009; Cummings \& Huse, 1989; King \& Anderson, 1990; Chatman \& Cha, 2003; Jaskyte, 2004). Moderating effect of risk taking on the link between transformational leadership and organizational innovation was examined through following hypothesis:

Hypothesis 2b: Risk taking moderates the relationship between transformational leadership and organizational innovation.

\section{Decision-making}

Previous studies identified that participating in decision-making is a strong determinant of innovative behavior. Participating in decision-making encourages employees to generate more ideas and may lead to increscent in their motivation to help with the implementation of ideas (Jong \& Hartog, 2007). In addition, quicker decisions would be taken, thus, converting and transferring new ideas into outputs, and representing something new for the organization will be done in a short time (Martins \& Martins, 2002). 


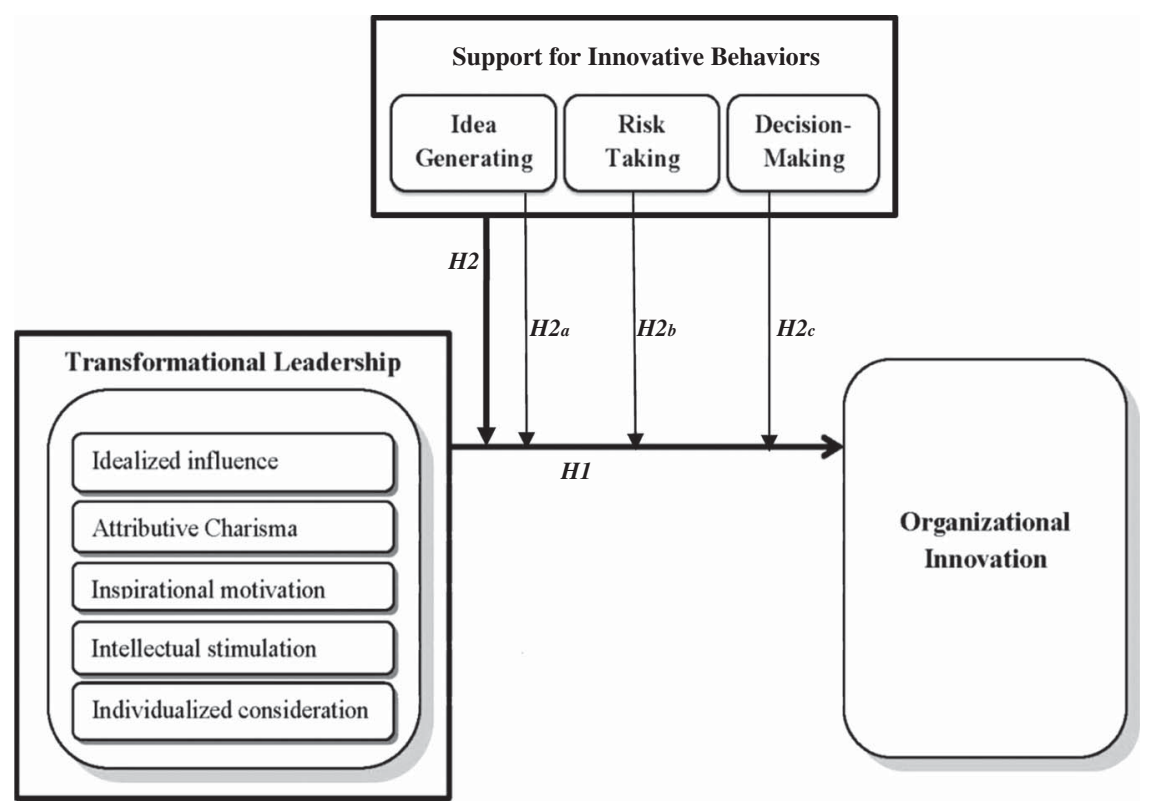

Figure 1. Conceptual framework of this research

The degree to which employees have freedom to participate in decision-making for solving problems defines level of empowerment by top management and the level of empowerment is positively related to the level of innovation in an organization (Arad, Hanson, \& Schneider, 1997: 4). Finally, in order to examine the moderating effect of decision-making on the relationship of transformational leadership and organizational innovation the following hypothesis was developed:

Hypothesis 2c: Decision-making moderates the relationship between transformational leadership and organizational innovation.

Therefore, with respect to the literature, and based on the theoretical and practical gaps, this study conceptualized the relationship of transformational leadership and organizational innovation with moderating effect of innovative behaviors as depicted in Figure 1.

\section{METHOD}

\section{Sample and procedure}

The sample of this research was compromised of 63 Iranian companies from both manufacturing and service sector in different industries. In this study, the population of interest was selected based on the list of top 100 Iranian companies (IMI-100). Under the plan of IMI-100, the top 100 Iranian companies are ranked each year through seven main indices (i.e., company's size, growth, profitability, performance, export liquidity, debt and market indexes) and published by Industrial Management Institute (IMI) in Iran. Of the top 100 Iranian companies, 77 companies fulfilled the criterion of this study as being listed in IMI-100 for three consecutive years. This criterion was employed to take into account the company's involvement in innovative activities constantly and continuously in a period of time. Of 77 organizations as the target population of this research, a sample of 63 organizations who 
were willing to participate in this research was selected. The perception of low-level and middle-level managers from their top leaders' transformational leadership style was the source of data in this research. In order to control the common response biases and avoid validity problems multiple data sources including (1) published financial statements and (2) IMI annual report of companies were used to double check and confirm each company's level of innovation. In addition, information on leadership behavior and the contextual variables was obtained from surveying managers with at least 3 years' work experience in their companies. Middle-level and low-level managers play a very important role in the organization. Middle-level managers are the people working under the top management levels and are directly responsible for the work of lower-level managers. They may have direct responsibility for other middle-level managers and low-level managers (Bartol et al., 2011). Low-level managers are also an important source of information about employees' satisfaction for higher management to take into account in their leadership behaviors. Therefore low-level and middle-level managers were asked to measure their top leader's extent of transformational leadership and their organization's support for innovative behaviors.

Data resulting from respondents in every organization were integrated in order to represent the respective organization. For this purpose, the joint probability of agreement was employed to support the inter-rater reliability of responses (James, Demaree, \& Wolf, 1984). This is the most robust measure which calculates the number of times each rating is assigned by each rater divided by the total number of ratings. The results of joint probability provided support for inter-rater reliability of data in this research. Then the rating average method was used to integrate four respondents to one unique data, which represents one organization (James et al., 1984). As all the participants in this research were Iranian, researchers used the Persian version of questions for which the copyright had been obtained.

\section{Respondents profile}

The sample of this study is regarded as highly homogeneous in terms of size of the firms. Companies which participated in this study are large-sized enterprises with more than 1,000 employees. Half of the respondents $(50.8 \%)$ were middle-level and senior managers and rests of them were low-level managers consisting of administrative, supervisors and manager assistants. In terms of gender and age, the majority of the survey respondents were male (85.7\%) and they were split between 35-45 years old $(36.6 \%)$ and $>45$ years old $(45.4 \%)$. On average they had been working for the current employer for 8.8 years $(\mathrm{SD}=5.44$ years). The vast majority $(90.5 \%)$ of respondents were well educated and had Bachelor's or Master's degree. On average organizations' age were 35 years which indicated that they were well-established companies.

\section{Measures}

\section{Transformational leadership}

This study measured the extent of transformational leadership using 20 items (four items for each component) from the Multifactor Leadership Questionnaire (MLQ-5X Rater Form) developed by Bass and Avolio (1997). Participants were asked to evaluate how frequently their top leader is engaged in transformational leadership behavior using a 5-point scale with $1=$ 'not at all' to $5=$ 'frequently, if not always.' Examples of items are 'the leader specifies the importance of having a strong sense of purpose' (idealized influence), 'the leader displays a sense of power and confidence' (attributed charisma), 'the leader talks enthusiastically about what needs to be accomplished' (inspirational motivation), 'the leader seeks differing perspectives when solving problems' (intellectual stimulation) and 'the leader helps me to develop my strengths' (individualized consideration). 


\section{Organizational innovation}

This study focuses on product innovations in defining organizational innovation. According to Damanpour (1991) product innovation is introducing new products or services to meet the market and external users' needs. This is interpreted as the successful bringing of new products or services to the market (Gumusluoglu \& Ilsev, 2009a). Therefore, in this research organizational innovation is defined as 'the tendency of organization to develop improved or new products/services and the successful bringing of those new products/services to the market.' According to Jung, Chow, and Wu (2008) the R\&D intensity and $\mathrm{R} \& \mathrm{D}$ expenditures only reflect the organization's 'willingness' to support innovation without considering the success of organization in generating innovative 'outcomes.' This study captured broader and more comprehensive aspect of organizational innovation. In this regard, two ratios, namely (1) the coefficient of innovativeness tendency and (2) the success of product innovation, were used to evaluate and measure organizational innovation. The coefficient of innovativeness tendency quantifies the innovativeness orientation of companies and is the ratio of sales generated by product innovations to total sales. The success of product innovations indicates the success of organization in both satisfying market needs and utilizing the organizations' resources in producing the innovations. This ratio is sales generated by product innovations over expenditures in producing those product innovations.

Besides, this study evaluates the product/service novelty, competitiveness of the organization and the newness of technology that has been used in the organization. Therefore, respondents were asked to evaluate product/service novelty, technology novelty and competitiveness using three questions adopted from adult population survey developed by Global Entrepreneurship Monitoring (2011). In conclusion, research instrument on organizational innovation in this study consists of six items which is used to produce an innovativeness index from a market and industry perspective.

\section{Innovative behaviors}

In line with theoretical findings of Martins and Martins (2002), idea generating, risk taking and decision-making are reidentified as behavioral elements that encourage innovation in the organization. To measure these behaviors the questions were adopted from the instrument developed by Martins (2000) to evaluate the employees' perception of the extent to which innovation is encouraged and supported in their organization. The question items to measure moderating effect of idea generating, risk taking and decision-making used 4-point Likert scale (1 = 'strongly disagree,' 2 = 'disagree,' 3 = 'agree,' 4 = 'strongly agree') to rate each item. Examples of items are 'people are encouraged to express their ideas and concerns' (idea generating), 'we are encouraged to take risks in adapting policies and procedures (rules and regulations) to changed circumstances' (risk taking) and 'purposeful action is taken to delegate decision-making to the appropriate lower levels' (decision-making).

\section{ANALYSIS AND RESULTS}

In this research, the hypotheses were tested using the PLS structural equation modeling technique (Wold, 1975) which is increasingly being used by leadership researchers (see Bass, Avolio, Jung, \& Berson, 2003; Jung, Chow, \& Wu, 2003, 2008; Howell, Neufeld, \& Avolio, 2005). In this study, SmartPLS software package 2.0.M3 was used for data analyses. PLS provides the measurement model, which includes an assessment of the reliability and validity of the measures and evaluate the structural model, which describes the relationship between dependent and independent variables (Götz, Liehr-Gobbers, \& Krafft, 2010) (see Table 1).

\section{Results for the measurement model}

In order to ensure the adequate reliability and validity of the constructs and measures, three criteria were employed in this study. First, the factor loadings of indicators associated with each constructs had 
Mozhdeh Mokhber, Wan Khairuzzaman and Amin Vakilbashi

Table 1. Descriptive statistics of constructs $(N=63$ companies)

\begin{tabular}{|c|c|c|c|c|}
\hline Construct & Indicator & Item & Mean & $S D$ \\
\hline \multirow[t]{20}{*}{ 1. Transformational leadership } & \multirow[t]{4}{*}{ Attributed charisma (AC) } & Q1.2.11.AC & 3.569 & 0.880 \\
\hline & & Q1.2.13.AC & 3.616 & 0.808 \\
\hline & & Q1.2.5.AC & 3.101 & 0.885 \\
\hline & & Q1.2.9.AC & 2.993 & 0.884 \\
\hline & \multirow[t]{4}{*}{ Individualized consideration (IC) } & Q1.5.10.IC & 3.265 & 0.825 \\
\hline & & Q1.5.15.IC & 3.245 & 0.899 \\
\hline & & Q1.5.17.IC & 3.080 & 0.873 \\
\hline & & Q1.5.8.IC & 3.340 & 0.828 \\
\hline & \multirow[t]{4}{*}{ Idealized influence (II) } & Q1.1.12.II & 3.505 & 0.865 \\
\hline & & Q1.1.19.II & 3.395 & 0.917 \\
\hline & & Q1.1.2.II & 3.470 & 0.926 \\
\hline & & Q1.1.7.II & 3.595 & 0.786 \\
\hline & \multirow[t]{4}{*}{ Inspirational motivation (IM) } & Q1.3.14.IM & 3.563 & 0.789 \\
\hline & & Q1.3.20.IM & 3.371 & 0.983 \\
\hline & & Q1.3.4.IM & 3.462 & 0.863 \\
\hline & & Q1.3.6.IM & 3.565 & 0.773 \\
\hline & \multirow{4}{*}{ Intellectual stimulation (IS) } & Q1.4.1.IS & 3.494 & 0.885 \\
\hline & & Q1.4.16.IS & 3.491 & 0.790 \\
\hline & & Q1.4.18.IS & 3.185 & 0.833 \\
\hline & & Q1.4.3.IS & 3.418 & 0.847 \\
\hline \multirow[t]{2}{*}{ 2. Organizational innovation } & & Innovation index & 1.893 & 0.444 \\
\hline & & Innovation ratio & 0.503 & 0.953 \\
\hline \multirow[t]{9}{*}{ 3. Innovative behaviors } & \multirow[t]{3}{*}{ Decision-making } & Q3.3.7 & 2.604 & 0.522 \\
\hline & & Q3.3.8 & 2.550 & 0.689 \\
\hline & & Q3.3.9 & 2.542 & 0.606 \\
\hline & \multirow{3}{*}{ Idea generating } & Q3.1.1 & 2.773 & 0.517 \\
\hline & & Q3.1.2 & 2.706 & 0.581 \\
\hline & & Q3.1.3 & 2.704 & 0.597 \\
\hline & \multirow[t]{3}{*}{ Risk taking } & Q3.2.4 & 2.414 & 0.606 \\
\hline & & Q3.2.5 & 2.621 & 0.520 \\
\hline & & Q3.2.6 & 2.572 & 0.563 \\
\hline
\end{tabular}

to be 0.7 or above (Götz, Liehr-Gobbers, \& Krafft, 2010) to ensure the indicator reliability. Second, the composite reliability for each construct had to exceed 0.7 (Götz, Liehr-Gobbers, \& Krafft, 2010) to indicate the adequate reliability of the constructs. Finally, the average variance extracted range must exceeds the recommended level of 0.50 (Götz, Liehr-Gobbers, \& Krafft, 2010) (see Table 2).

In order to test the constructs' convergent and discriminant validity, additional analyses were run by comparing the average variance extracted and correlation between constructs. A comparison of the correlation with the square root of average variance extracted (as shown in bold in Table 3) indicates that all correlations between two constructs are less than the square root of average variance extracted of both groups (Fornell \& Larcker, 1981). Moreover, the result of cross-loadings in this research showed that each measurement item correlates weakly with all other constructs except for the one to which it is theoretically associated. Therefore the results supported adequate convergent and discriminant validity of the constructs in the model (see Table 3).

\section{Results for the structural model and hypotheses}

A satisfactory evaluation of the structural model in PLS must consist three indexes including path coefficients, squared multiple correlations $\left(R^{2}\right)$ and $t$-value. As true path coefficients, values of 0.00 , 
TABLE 2. FACtOR LOAdINGS, COMPOSITE RELIABILITY AND AVERAGE VARIANCE EXTRACTED FOR ASSESSING CONSTRUCT RELIABILITY

\begin{tabular}{|c|c|c|c|c|c|}
\hline Constructs & Indicator & Item & $\begin{array}{l}\text { Factor } \\
\text { loadings }\end{array}$ & $\begin{array}{l}\text { Composite } \\
\text { reliability }\end{array}$ & $\begin{array}{c}\text { Average variance } \\
\text { extracted }\end{array}$ \\
\hline \multirow{2}{*}{$\begin{array}{l}\text { 1. Organizational } \\
\text { innovation }\end{array}$} & Innovation index & Innoindex & 0.908 & \multirow[t]{2}{*}{0.83} & \multirow[t]{2}{*}{0.72} \\
\hline & Innovation ratios & Innoratio & 0.782 & & \\
\hline \multirow{20}{*}{$\begin{array}{l}\text { 2. Transformational } \\
\text { leadership }\end{array}$} & \multirow[t]{4}{*}{ Idealized influence (II) } & Q1.1.12.II & 0.882 & \multirow[t]{20}{*}{0.96} & \multirow[t]{20}{*}{0.85} \\
\hline & & Q1.1.19.II & 0.852 & & \\
\hline & & Q1.1.2.II & 0.769 & & \\
\hline & & Q1.1.7.II & 0.923 & & \\
\hline & \multirow[t]{4}{*}{ Attributed charisma (AC) } & Q1.2.11.AC & 0.893 & & \\
\hline & & Q1.2.13.AC & 0.800 & & \\
\hline & & Q1.2.5.AC & 0.912 & & \\
\hline & & Q1.2.9.AC & 0.816 & & \\
\hline & \multirow[t]{4}{*}{ Inspirational motivation (IM) } & Q1.3.14.IM & 0.850 & & \\
\hline & & Q1.3.20.IM & 0.908 & & \\
\hline & & Q1.3.4.IM & 0.830 & & \\
\hline & & Q1.3.6.IM & 0.924 & & \\
\hline & \multirow[t]{4}{*}{ Intellectual stimulation (IS) } & Q1.4.1.IS & 0.906 & & \\
\hline & & Q1.4.16.IS & 0.849 & & \\
\hline & & Q1.4.18.IS & 0.763 & & \\
\hline & & Q1.4.3.IS & 0.880 & & \\
\hline & \multirow[t]{4}{*}{ Individualized consideration (IC) } & Q1.5.10.IC & 0.875 & & \\
\hline & & Q1.5.15.IC & 0.900 & & \\
\hline & & Q1.5.17.IC & 0.937 & & \\
\hline & & Q1.5.8.IC & 0.763 & & \\
\hline \multirow{9}{*}{$\begin{array}{l}\text { 3. Innovative } \\
\text { behaviors }\end{array}$} & \multirow[t]{3}{*}{ Idea generating } & Q3.1.1 & 0.865 & \multirow[t]{3}{*}{0.90} & \multirow[t]{3}{*}{0.75} \\
\hline & & Q3.1.2 & 0.928 & & \\
\hline & & Q3.1.3 & 0.811 & & \\
\hline & \multirow[t]{3}{*}{ Risk taking } & Q3.2.4 & 0.844 & \multirow[t]{3}{*}{0.92} & \multirow[t]{3}{*}{0.79} \\
\hline & & Q3.2.5 & 0.938 & & \\
\hline & & Q3.2.6 & 0.897 & & \\
\hline & \multirow[t]{3}{*}{ Decision- making } & Q3.3.7 & 0.922 & \multirow[t]{3}{*}{0.94} & \multirow[t]{3}{*}{0.84} \\
\hline & & Q3.3.8 & 0.917 & & \\
\hline & & Q3.3.9 & 0.916 & & \\
\hline
\end{tabular}

Table 3. Average variance extracted (AVE), constructs' intercorrelation and souare root of AVE for ASSESSING CONVERGENT AND DISCRIMINANT VALIDITY

\begin{tabular}{|c|c|c|c|c|c|c|c|}
\hline & AVE & $D M$ & IG & $\mathrm{Ol}$ & $R T$ & $T L$ & \\
\hline Decision-making (DM) & 0.843 & 1.000 & 0.91 & & & & \\
\hline Idea generating (IG) & 0.756 & 0.832 & 1.000 & 0.86 & & & \\
\hline Organizational innovation (OI) & 0.725 & 0.461 & 0.604 & 1.000 & 0.85 & & \\
\hline Risk taking $(\mathrm{RT})$ & 0.799 & 0.836 & 0.786 & 0.574 & 1.000 & 0.89 & \\
\hline Transformational leadership (TL) & 0.859 & 0.735 & 0.743 & 0.630 & 0.711 & 1.000 & 0.92 \\
\hline
\end{tabular}

Note. A comparison of the correlation with the square root of average variance extracted values are given in bold.

$0.15,0.35$ and 0.50 are representing a non-existent, weak, moderate and strong effect (Henseler, Fassott, Dijkstra, \& Wilson, 2012). In order to evaluate predictive strength of the model, $R^{2}$ will be calculated for the dependent latent variable. The high values of $R^{2}$ verify the good fitness and validity of 
TABle 4. The Results of DiRect AND moderating efFects

\begin{tabular}{|c|c|c|c|c|c|c|c|}
\hline & \multicolumn{3}{|c|}{ Model 1: direct effect } & \multicolumn{4}{|c|}{ Model 2: interaction effects } \\
\hline & $\beta$ & t-Value & $R^{2}$ & $\beta$ & t-Value & $R^{2}$ & $\Delta R^{2}$ \\
\hline $\begin{array}{l}\text { Transformational leadership } \rightarrow \text { organizational innovation } \\
\text { (Hypothesis 1) }\end{array}$ & 0.670 & $13.118^{\star \star \star}$ & $44.9 \%$ & & & & \\
\hline $\begin{array}{l}\text { Transformational leadership } \rightarrow \text { organizational } \\
\text { innovation }+ \text { innovative behaviors (Hypothesis } 2 \text { ) }\end{array}$ & & & & 0.30 & 2.14 & 51.3 & 6.4 \\
\hline $\begin{array}{l}\text { Transformational leadership } \rightarrow \text { organizational innovation }+ \\
\text { idea generating (Hypothesis 2a) }\end{array}$ & & & & 0.299 & $2.061^{\star}$ & $53.0 \%$ & 8.1 \\
\hline $\begin{array}{l}\text { Transformational leadership } \rightarrow \text { organizational innovation }+ \\
\quad \text { risk taking (Hypothesis } 2 b \text { ) }\end{array}$ & & & & 0.302 & $2.222^{\star}$ & $52.3 \%$ & 7.4 \\
\hline $\begin{array}{l}\text { Transformational leadership } \rightarrow \text { organizational innovation } \\
\quad+\text { decision-making (Hypothesis } 2 \mathrm{c} \text { ) }\end{array}$ & & & & 0.081 & 0.710 & $45.3 \%$ & 0.4 \\
\hline
\end{tabular}

Note. ${ }^{*} t \geq 1.96$ at $p=.05$ level; ${ }^{\star \star} t \geq 2.58$ at $p=.01$ level; ${ }^{\star \star *} t \geq 3.29$ at $p=.001$ level.

the built model (Götz, Liehr-Gobbers, \& Krafft, 2010). Finally, $t$-values are obtained through the bootstrap routine and must be $>1.96$ (Chin, 1998).

\section{Direct effects}

In this research, the results supported positive impact of transformational leadership on organizational innovation. The PLS analysis showed that transformational leadership as a whole construct accounted for about $45 \%$ of the variance $\left(R^{2}=0.449, \beta=0.670, t \geq 3.29, p<.001\right)$ in organizational innovation.

\section{Moderating effects}

PLS proposes a product indicator approach to measure moderating effect and the effect size $\left(f^{2}\right)$ can be assessed by comparing the proportion of $R^{2}$ of the model without moderating effect with $R^{2}$ of the model with moderating effect using the formula suggested by Cohen (1988).

Based on the results in this study the second hypothesis was supported $\left(R^{2}=0.449\right.$ vs. 0.513 ; $\left.\Delta R^{2}=6.4, \beta=0.30, t \geq 1.96, p<.05\right)$ and this revealed that innovative behaviors can positively moderate the relationship between transformational leadership and organizational innovation.

The result of the sub-hypothesis Hypothesis 2a indicated higher $R^{2}$ with the presence of idea generating as moderating variable in the model $\left(R^{2}=0.449\right.$ vs. $\left.0.53 ; \Delta R^{2}=8.1, \beta=0.29, t \geq 1.96, p<.05\right)$ and the effect size $\left(f^{2}\right)$ of idea generating can be considered as a large effect $\left(f^{2}=0.17\right)$ (Aguinis, Beaty, Boik, \& Pierce, 2005). Similarly, it has been found that risk taking can positively moderate the relationship between transformational leadership and organizational innovation $\left(R^{2}=0.449\right.$ vs. $0.523 ; \Delta R^{2}=7.4$, $\beta=0.30, t \geq 1.96, p<.05)$ and the effect size $\left(f^{2}=0.156\right)$ of risk taking is also large (Aguinis et al., 2005). Finally, the results revealed that participating in decision-making does not moderate the relationship between transformational leadership and organizational innovation and changes in $R^{2}$ was not significant $\left(R^{2}=0.449\right.$ vs. $\left.0.453 ; \Delta R^{2}=0.4, \beta=0.08, t<1.96\right)$ (see Table 4).

\section{DISCUSSION}

\section{Discussion of findings on first hypothesis}

Hypothesis 1: Transformational leadership is positively related to organizational innovation. 
The results of this research supported a direct and positive effect of transformational leadership on organizational innovation. Past empirical literature exhibited associations between transformational leadership and innovation. A study by Jung, Chow, and Wu (2003) revealed positive and significant relationship between transformational leadership and firm's innovation. Gumusluoglu and Ilsev (2009b) also found that transformational leadership positively affects organization's tendency to innovate. The results of this study are consistent with the findings of previous literature and provide strong empirical evidence.

At the organizational level of analysis, in line with the findings of Jung, Chow, and Wu (2003, 2008), this study supported that transformational leadership has a significant positive association with organizational innovation. The study of Gumusluoglu and Ilsev (2009a) also revealed that transformational leadership is positively associated with individual and organizational creativity and has an important effect on organizational innovation. In line with Gumusluoglu and Ilsev (2009a) transformational leadership was found to have a high correlation (0.67) with organizational innovation in this research. The effect of transformational leaders on innovation might be directly through effecting employees' creativity (Oldham \& Cummings, 1996) and indirectly through changes in organizational characteristics (Woodman, Sawyer, \& Griffin, 1993) such as culture, strategy, structure and resources. Previous studies investigated the effect of leadership mostly on the tendency of organization to innovate. But in line with Gumusluoglu and Ilsev (2009b) in this research success of innovations is concerned as well as the tendency to innovate. The results of this study suggest that as transformational leadership increases, innovation in the organization increases. This result is also consistent with the collectivistic character of Iranian respondents. According to Hofstede (2012) Iran is considered as a collectivistic society and this supports the opinion by Bass (1990) that transformational leadership is more likely to appear in collectivist cultures rather than in the individualist cultures. In collectivism culture employees expect their leaders to show transformational behaviors and they readily respond to this type of leadership. A number of studies also reported a strong positive effect of transformational leadership on organizational innovation in collectivist culture (e.g., Avolio, Bass, \& Jung, 1999; Jung \& Avolio, 1999; Jung \& Yammarino, 2001; Jung, Chow, \& Wu, 2003, 2008; Gumusluoglu \& Ilsev, $2009 \mathrm{~b})$. Based on the findings and results it can be interpreted that organizations can improve their innovativeness by helping managers to develop and display transformational leadership behaviors (Jung, Chow, \& Wu, 2008).

\section{Discussion of findings on second hypothesis}

Hypothesis 2: Support for innovative behaviors moderate the relationship between transformational leadership and organizational innovation.

Testing second hypothesis certified that organization support for innovative behaviors moderate the relationship of transformational leadership and organizational innovation. In line with theoretical findings of Martins and Martins (2002), in this research innovative behaviors (i.e., idea generation, risk taking and decision-making) are behavioral elements that encourage innovation in the organization. Mumford and Gustafson (1988) argued that even when employees develop their capacities for innovation, being worried on the consequences of innovative efforts in the organization environment may affect their undertaken actions. Oke, Munshi, and Walumbwa (2009) confirmed that the effect of transformational leadership on innovation will be moderated by organizational contexts that encourage innovative behaviors and culture.

Findings of the study by Jung, Chow, and Wu (2008) revealed that transformational leadership by top manager can improve organizational innovation directly and also indirectly through building an 
organizational culture supportive of innovative behaviors in which employees are encouraged to present innovative activities. They noted that, when there is not a supportive climate for innovation in organization the transformational leaders' behavior may only slightly stimulate followers toward innovation (Jung, Chow, \& Wu, 2008). Therefore it can be concluded that in the sample of this study, managers have the perception of an organization which is supportive of innovation. In this regard, the effect of transformational leadership on organizational innovation increases (effect size $=0.13$ ) and more percentage of the variance in organizational innovation is explained by the interaction of transformational leadership and innovative behaviors $(R=0.51)$.

Hypothesis 2a: Idea generating moderates the relationship between transformational leadership and organizational innovation.

Testing this hypothesis certified that idea generating moderates the relationship of transformational leadership and organizational innovation. In other words, when employees feel welcome to present new ideas without being worried to be judged unfairly by the organization and top manager, then the interaction effect of idea generating and transformational leadership strengthen the effect of transformational leadership on organizational innovation.

Albrecht and Hall (1991) found that generating and suggesting new ideas is representing change to an established order and perceived to be quite risky. Generating and presenting new ideas cannot be separated from the person offering the idea and is usually along with evaluation of organizational members. Research has demonstrated that innovative behaviors increase when employees feel that new ideas are expected and encouraged and they can express their ideas freely without being criticized or punished for mistakes (Jong \& Hartog, 2007).

Considering and supporting idea generation in the organization will motivate employees to constantly try new things for the purpose of improving organizational processes and launching product innovation. This may lead to renewing the structure, processes and methods of the organization and, respectively, increases organizational innovation. According to Martins and Martins (2002), idea generating involves encouragement of generating new ideas, selling good ideas, giving credit for ideas and encouraging employees to take steps to find new ways of problem solving. Oke, Munshi, and Walumbwa (2009) proposed that the effect of transformational leadership on innovation will be higher where some organizational contexts such as facilitating idea generation are present and active rather than they are inactive or absent. It can be concluded that in the sample of this study, managers have the perception of an organization which is supportive of idea generating. In this regard, the effect of transformational leadership on organizational innovation increases (effect size $=0.17$ ) and more percentage of the variance in organizational innovation is explained by the interaction of transformational leadership and idea generating $\left(R^{2}=0.44\right.$ vs. $\left.R=0.53\right)$.

Hypothesis 2b: Risk taking moderates the relationship between transformational leadership and organizational innovation.

Risk taking and experimentation are closely related to innovation (Martins \& Terblanche, 2003). As innovation requires risk taking and long-term investment, employees need to perceive that organization supports more innovative and risky ideas (Jung, Chow, \& Wu, 2008). Several authors confirmed that creating values supportive of risk taking in the organization increase the acceptance of leader by the employees and lead to shaping the organization's level of innovativeness (Hasenfeld, 1983; Cummings \& Huse, 1989; King \& Anderson, 1990; Chatman \& Cha, 2003; Jaskyte, 2004).

Based on the findings of Jung, Chow, and Wu (2003), too much management control in the organization will hinder risk taking and innovation. When taking risks, it is important to believe that there is always a good chance of success. So it is worth to be responsible of monitoring and measuring risk taking while providing a tolerant organizational environment to accept mistakes (Martins \& Terblanche, 2003). 
It is important to understand that possibility of success in risk taking can largely motivate innovative employees. In this regard, it is necessary to create a culture that increases the success of risk taking by providing balance between allowing freedom to employees in taking risks while allowing for moderate risk taking (Martins \& Martins, 2002). It can be concluded that in the sample of this study, managers have the perception of an organization which is supportive of risk taking. In this regard, the effect of transformational leadership on organizational innovation increases (effect size $=0.15$ ) and more percentage of the variance in organizational innovation is explained by the interaction of transformational leadership and risk taking $\left(R^{2}=0.44\right.$ vs. $\left.R=0.52\right)$.

Hypothesis 2c: Decision-making moderates the relationship between transformational leadership and organizational innovation.

Testing the last hypothesis in this study revealed that participating in decision-making does not moderates the relationship of transformational leadership and organizational innovation.

Previous studies identified that participation in decision-making is a strong determinant of innovative behavior (Jong \& Hartog, 2007). Findings of previous studies revealed that the degree to which employees have freedom to participate in decision-making for solving problems determines level of empowerment and the level of empowerment is positively related to the level of innovation in an organization (Arad, Hanson, \& Schneider, 1997: 4). The speed of decision-making can also promote or inhibit creativity and innovation.

Contrary to the expectation of this study, hypothesized moderating effect of decision-making on the relationship of transformational leadership and organizational innovation was not supported in this research. A possible explanation of this unexpected result might be the culture of Iranian managers and leadership in Iran. Findings of study by Javidan and Dastmalchian (2003) indicated that middle-level managers did not believe in participatory leadership. Some researchers suggested that participation in decision-making has a different meaning in a country like Iran (Javidan \& Dastmalchian, 2003). They described that participation among Iranian managers is mostly perceived as a means of achieving harmony in groups rather than improving the quality of decision. Based on the study of Javidan and Dastmalchian (2003: 137) on the relationship of culture and leadership in Iran, it has been identified that Iranian managers used autocratic leadership, who make decisions without much participation from their followers. Therefore the interaction effect of decision-making and transformational leadership was not significant in this research.

\section{RESEARCH IMPLICATIONS}

Findings of this study highlight the empirical analysis of transformational leadership behaviors in the organizational context by investigating a new set of moderating variables. To our knowledge this study is the first examining direct and moderated effect of transformational leadership on organizational innovation in Iran as a developing country and can expand our understanding of leadership and innovation in countries that share similar conditions and structures with Iran. Iranian specialists have realized the need for stimulating diversification, technology development and innovation. Enterprises in Iran are mainly weak in innovation activities and need to be strengthened. In recent years, the government has started encouraging organizations to build their research and development units but it has been limited regarding the actual innovation activities at the organizational level. Although Iran is rich in terms of natural resources and well-educated human resource, this potential advantage is not yet beneficial for achieving an innovation-driven growth due to the weaknesses in innovation system (United Nations, 2005). All the specifications of research population in terms of the size of companies, combination of services and manufacturing industries along with the presence of leading companies from the most important Iranian industries indicate that this study has multilevel contribution and is 
the best choice to represent the country's economy and business environment. This research was conducted among listed top 100 Iranian companies. The IMI-100 list encompasses the most important companies from both services and manufacturing industries. Although these two sectors together contribute for $89.7 \%$ of Iran's gross domestic product (GDP), population of this research is a good representative of country's economy in both service and manufacturing industries. In addition, the target population of this research consist of the most important manufacturing industries in Iran. For example, IMI-100 includes 38 companies from automotive industry, which is the second most active industry of the country, accounting for 10\% of Iran's GDP. The IMI-100 also includes almost 15 companies from oil and gas industry, which is the first most active industry in Iran, and plays an important role in the country's economy. Therefore this study may provide insights into understanding transformational leadership and organizational innovation for the managers who are currently working or have plans to work in developing countries and organizations similar to Iran.

Findings of this research emphasize that the support received by employees from the organization may strengthen the effect of transformational leadership on organizational innovation. Thus it is important for managers to fit their leadership behaviors to the organizational context in which they work. Organizations can improve their innovativeness by selecting and recruiting top managers and CEOs who display transformational leadership behaviors and helping them to improve such behaviors through training and mentoring processes. Finally, this study sends practitioners and board of directors the message that when evaluating leaders and top managers, it is important to consider rewarding them based on the behaviors that support transformational style of leadership, which are more effective predictors of innovation in the organization.

\section{LIMITATIONS AND FUTURE RESEARCH DIRECTIONS}

Although several encouraging results have been found in this research, however the following limitations may describe the need for future studies. First of all, this study employed the Multifactor Leadership Questionnaire employee form for participants to rate the perception of employees from their top managers' leadership. Further investigation of these findings based on both employees' and leaders' ratings may lead to different or similar results. Moreover, the theoretical evidence between the five subelements of the transformational leadership and the organizational innovation and support for innovative behaviors could be further elaborated in the future studies. This may extend our understanding of how each element contribute to stimulation of innovation in the organization with moderating role of support for innovative behaviors. Second, current study can only reveal correlation but not causation. Hence, as a possible direction for future research, it is good to effectively examine this issue based on a cross-level analysis. The nonsignificant moderating effect of decision-making on the relationship of transformational leadership and organizational innovation would be a possible direction for future research as the results may well vary across the cultures. Finally, as this research aimed to measure the transformational behavior of top leaders in the listed organizations and due to high sensitivity of the questions, the data were collected based on purposive sampling method. Therefore generalization of the results should be made with caution.

\section{CONCLUSION}

The ability to innovate continuously by providing creative efforts and required knowledge and skills is the key to the competitiveness of organizations. Leadership at the top, with its significant impact on development of the organizational vision and the strategies to accomplish that vision, seems to be an important antecedent of organization's ability to innovate. The advantages of transformational leadership in stimulating organizational innovation can be reinforced by organizational context that 
support innovation and the overall performance of the organization may greatly improve at every organizational level. Therefore, to enhance the level of organizational innovation, there should be organizational support to encourage employees generating and presenting new ideas while feeling free to take risks. Likewise, programs and policies that are related to such organizational supports must be developed and implemented in the organizations.

\section{ACKNOWLEDGEMENT}

Many thanks to our friends, organizations and those who participated in this research and provided insights and expertise that greatly assisted the research progress. We are also immensely grateful to the anonymous reviewers for their helpful comments and suggestions during the review process.

\section{References}

Aguinis, H., Beaty, J. C., Boik, R. J., \& Pierce, C. A. (2005). Effect size and power in assessing moderating effects of categorical variables using multiple regression: A 30-year review. Journal of Applied Psychology, 90, 94-107.

Albrecht, T. L., \& Hall, B. J. (1991). Facilitating talk about new ideas: The role of personal relationships in organizational innovation. Communications Monographs, 58(3), 273-288.

Amabile, T. M. (1998). How to kill creativity. Harvard Business Review, 76(9), 77-87.

Arad, S., Hanson, M. A., \& Schneider, R. J. (1997). A framework for the study of relationships between organizational characteristics and organizational innovation. The Journal of Creative Behavior, 31(1), 42-58.

Avolio, B. J. (2003). Examining the full range model of leadership: Looking back to transform forward. Leadership development for transforming organizations: Grow leaders for tomorrow, 71-98.

Avolio, B. J., \& Bass, B. M. (1991). The full range leadership development programs: Basic and advanced manuals Binghamlon, NY: Bass. Avolio \& Associates.

Avolio, B. J., Bass, B. M., \& Jung, D. I. (1999). Re-examining the components of transformational and transactional leadership using the Multifactor Leadership. Journal of occupational and organizational psychology, 72(4), 441-462.

Bartol, K., Tein, M., Matthews, G., Sharma, B., \& Scott-Ladd, B. (2011). Management foundations: a Pacific Rim focus. 3rd edition.

Bass, B. (1985). Leadership and performance beyond expectations. New York, NY: Free Press.

Bass, B. M. (1990). From transactional to transformational leadership: Learning to share the vision. Organizational dynamics, 18(3), 19-31.

Bass, B., \& Avolio, B. J. (1997). Revised manual for the multifactor leadership questionnaire. Palo Alto, CA: Mind Garden.

Bass, B., Avolio, B. J., Jung, D., \& Berson, Y. (2003). Predicting unit performance by assessing transformational and transactional leadership. Journal of Applied Psychology Bulletin, 88(2), 207-218.

Bass, B., \& Riggio, R. E. (2006). Transformational leadership. Mahwah, NJ: L. Erlbaum Associates.

Chatman, J. A., \& Cha, S. E. (2003). Leading by leveraging culture. California management review, 45(4), 20-34.

Chin, W. (1998). The partial least squares approach to structural equation modeling. In G. A. Marcoulides (Ed.), Modern methods for business research (pp. 295-336). Mahwah, NJ: L. Erlbaum Associates.

Choi, S. B., Kim, K., Ullah, S. E., \& Kang, S. W. (2016). How transformational leadership facilitates innovative behavior of Korean workers: Examining mediating and moderating processes. Personnel Review, 45(3), 459-479.

Cohen, J. (1988). Statistical power analysis for the behavioral sciences. New Jersey: Lawrence Erlbaum Associates. Inc. Publishers.

Conger, J. A. (1999). Charismatic and transformational leadership in organizations: An insider's perspective on these developing streams of research. The Leadership Quarterly, 10(2), 145-179.

Cummings, T. G., \& Huse, E. F. (1989). Organizational Development and Change. Saint Paul, Minn.: West.

Daft, R. L. (1978). A dual-core model of organizational innovation. Academy of Management Review, 21(2), 193-210.

Damanpour, F. (1991). Organizational innovation: A meta-analysis of effects of determinants and moderators. Academy of Management Journal, 34(5), 55-90.

Damanpour, F. (1996). Organizational complexity and innovation: Developing and testing multiple contingency models. Management Science, 42(5), 693-716. 
Damanpour, F., \& Evan, W. M. (1984). Organizational innovation and performance: The problem of organizational lag. Administrative Science Quarterly, 29(3), 392-402.

Feng, C., Huang, X., \& Zhang, L. (2016). A multilevel study of transformational leadership, dual organizational change and innovative behavior in groups. Journal of Organizational Change Management, 29(6), 855-877.

Fiedler, F. E. (1964). A contingency model of leadership effectiveness. Advances in experimental social psychology, 1, 149-190.

Fornell, C., \& Larcker, D. F. (1981). Evaluating structural equation models with unobservable variables and measurement error. Journal of marketing research, 39-50.

García-Morales, V. J., Matías-Reche, F., \& Hurtado-Torres, N. (2008). Influence of transformational leadership on organizational innovation and performance depending on the level of organizational learning in the pharmaceutical sector. Journal of Organizational Change Management, 21(2), 188-212. https://doi.org/10.1108/09534810810856435.

Gardner, W. L., \& Avolio, B. A. (1998). The charismatic relationship: A dramaturgical perspective. Academy of Management Review, 23(1), 32-58.

Götz, O., Liehr-Gobbers, K., \& Krafft, M. (2010). Evaluation of structural equation models using the partial least squares (PLS) approach. In V. Esposito Vinzi, W. W. Chin, J. Henseler, \& H. Wang (Eds.), Handbook of partial least squares (pp. 691-711). Berlin, Heidelberg: Springer.

Gudergan, S. P., Ringle, C. M., Wende, S., \& Will, A. (2008). Confirmatory tetrad analysis in PLS path modeling. Journal of Business Research, 61(12), 1238-1249. https://doi.org/10.1016/j.jbusres.2008.01.012.

Gumusluoglu, L., \& Ilsev, A. (2009a). Transformational leadership and organizational innovation: The roles of internal and external support for innovation. Journal of Product Innovation Management, 26, 264-277.

Gumusluoglu, L., \& Ilsev, A. (2009b). Transformational leadership, creativity, and organizational innovation. Journal of Business Research, 62(4), 461-473. https://doi.org/10.1016/j.jbusres.2007.07.032.

Hage, J. (Ed.) (1998). Organizational innovation (Vol. 15) Dartmouth Publishing Company.

Hasenfeld, Y. (2009). Human services as complex organizations. Sage Publications.

Henseler, J., Fassott, G., Dijkstra, T. K., \& Wilson, B. (2012). Analysing quadratic effects of formative constructs by means of variance-based structural equation modelling. European Journal of Information Systems, 21, 99-112.

Hofstede, G. (2012). National Culture, countries, 2012, from http://geert-hofstede.com/iran.html.

Howell, J. M., Neufeld, D., \& Avolio, B. (2005). Examining the relationship of leadership and physical distance with business unit performance. The Leadership Quarterly, 16(2), 273-285.

House, R. J., Filley, A. C., \& Gujarati, D. N. (1971). Leadership style, hierarchical influence, and the satisfaction of subordinate role expectations: A test of Likert's influence proposition. Journal of Applied Psychology, 55(5), 422-432.

Hsiao, H. C., Chang, J. C., \& Tu, Y. L. (2009, December). The influence of transformational leadership and support for innovation on organizational innovation: from the vocational high school teachers' perspective. In Industrial Engineering and Engineering Management, 2009. IEEM 2009. (pp. 1988-1992). IEEE International Conference on IEEE.

Imran, R., \& Anis-ul-Haque, M. (2011). Mediating effect of organizational climate between transformational leadership and innovative work behaviour. Pakistan Journal of Psychological Research, 26(2), 183-199.

James, L. R., Demaree, R. G., \& Wolf, G. (1984). Estimating within-group interrater reliability with and without response bias. Journal of applied psychology, 69(1), 85.

Jaskyte, K. (2004). Transformational leadership, organizational culture, and innovativeness in nonprofit organizations. Nonprofit Management and Leadership, 15(2), 153-168. https://doi.org/10.1002/nml.59.

Javidan, M., \& Dastmalchian, A. (2003). Culture and leadership in Iran: The land of individual achievers, strong family ties, and powerful elite. Building Effective Networks, 17(4), 127-142.

Jong, J. P. J., \& Hartog, D. N. (2003). Leadership as a determinant of innovative behaviour: A conceptual framework. The Netherlands: EIM Business \& Policy Research.

Jong, J. P. J. d., \& Hartog, D. N. D. (2007). How leaders influence employees' innovative behaviour. European Journal of Innovation Management, 1O(1), 41-64. https://doi.org/10.1108/14601060710720546.

Jung, D., Chow, C., \& Wu, A. (2003). The role of transformational leadership in enhancing organizational innovation: Hypotheses and some preliminary findings. The Leadership Quarterly, 14(4-5), 525-544. https://doi.org/10.1016/ s1048-9843(03)00050-x.

Jung, D., Chow, C., \& Wu, A. (2008). Towards understanding the direct and indirect effects of CEOs' transformational leadership on firm innovation. The Leadership Quarterly, 19(5), 582-594. 
Jung, D. I., \& Avolio, B. J. (1999). Effects of leadership style and followers' cultural orientation on performance in group and individual task conditions. Academy of management journal, 42(2), 208-218.

Jung, D. I., \& Yammarino, F. J. (2001). Perceptions of transformational leadership among Asian Americans and Caucasian Americans: A level of analysis perspective. Journal of Leadership \& Organizational Studies, 8(1), $3-21$.

Khan, R., Rehman, A. U., \& Fatima, A. (2009). Transformational leadership and organizational innovation: Moderated by organizational size. African Journal of Business Management, 3(11), 678-684.

King, N., \& Anderson, N. (1990). Innovation in working groups.

Makri, M., \& Scandura, T. A. (2010). Exploring the effects of creative CEO leadership on innovation in high-technology firms. The Leadership Quarterly, 21(1), 75-88. https://doi.org/10.1016/j.leaqua.2009. 10.006 .

Martins, E. (2000). Die invloed van organisasiekultuur op kreatiwiteit en innovasie in ' $n$ universiteitbiblioteek [The influence of organisational culture on creativity and innovation in a university library]. MA dissertation. University of South-Africa, Pretoria.

Martins, E., \& Martins, N. (2002). An organizational culture model to promote creativity and innovation. Journal of Industrial Psychology, 28(4), 58-65.

Martins, E., \& Terblanche, F. (2003). Building organisational culture that stimulates creativity and innovation. European Journal of Innovation Management, 6(1), 64-74.

Mumford, M. D. (2002). Leading creative people: Orchestrating expertise and relationships. The Leadership Quarterly, 13(6), 705-750.

Mumford, M. D., \& Gustafson, S. B. (1988). Creativity syndrome: Integration, application, and innovation. Psychological bulletin, 103(1), 27.

Oke, A., Munshi, N., \& Walumbwa, F. (2009). The influence of leadership on innovation processes and activities. Organizational Dynamics, 38(1), 64-72. https://doi.org/10.1016/j.orgdyn.2008.10.005.

Oldham, G. R., \& Cummings, A. (1996). Employee creativity: Personal and contextual factors at work. Academy of Management Journal, 39(3), 607-655.

Pieterse, A. N., Van Knippenberg, D., Schippers, M., \& Stam, D. (2010). Transformational and transactional leadership and innovative behavior: The moderating role of psychological empowerment. Journal of Organizational Behavior, 31(4), 609-623.

Poppendick, P. (2009). Direct and indirect effects of transformational leadership on innovative behavior (Bachelor's thesis, University of Twente).

Prasad, B., \& Junni, P. (2016). CEO transformational and transactional leadership and organizational innovation: The moderating role of environmental dynamism. Management Decision, 54(7), 1542-1568.

Rosing, K., Frese, M., \& Bausch, A. (2011). Explaining the heterogeneity of the leadership-innovation relationship: Ambidextrous leadership. The Leadership Quarterly, 22(5), 956-974.

Sarros, J. C., Cooper, B. K., \& Santora, J. C. (2008). Building a climate for innovation through transformational leadership and organizational culture. Journal of Leadership \& Organizational Studies, 15(2), 145-158. https://doi. org/10.1177/1548051808324100.

Shin, J. (1996). The effects of executive leadership on organizational innovation in nonprofit. In Human Service Organizations (HSOs). University of Pittsburgh.

Slappendel, C. (1996). Perspectives on innovation in organizations. Organization Studies, 17(1), 107-129. https://doi. org/10.1177/017084069601700105.

Tsai, C. T., \& Chen, K. F. (2010). When Transformational Leadership and Learning Orientation Impact on Innovation Behavior: The Importance of Ambidextrous Organization. In International Conference on Business and Information, Japan.

Tsai, C. T., \& Tseng, W. W. (2010). A research agenda of transformational leadership and innovative behavior for the hospitality industry: An integrated multilevel model. Paper presented at the Annual International Council on Hotels Restaurants and Institutional Education Conference, Puerto Rico, USA.

United Nations, Science, Technology and Innovation Policy Review: Islamic Republic of Iran, United Nations Publication, 2005.

Van Knippenberg, D., \& Hogg, M. A. (2003). A social identity model of leadership effectiveness in organizations. Research in organizational behavior, 25, 243-295. 
Wold, H. (1975). Path models with latent variables: The NIPALS approach. In H. M. Blalock, A. Aganbegian, F. M. Borodkin, R. Boudon, \& V. Capecchi (Eds.), Quantitative sociology: International perspectives on mathematical and statistical modeling (pp. 307-357). New York, NY: Academic Press.

Woodman, R. W., Sawyer, J. E., \& Griffin, R. W. (1993). Toward a theory of organizational creativity. Academy of Management Review, 18(2), 293-321.

Yukl, G. A. (2002). Leadership in organizations.

\section{About the authors}

Mozhdeh Mokhber is a senior lecturer of management at International Business School (IBS) in Universiti Teknologi Malaysia (UTM). She is currently responsible for academic programs at UTM IBS. Her research interests include leadership, creativity and innovation, organizational behavior and change management. She is an author and co-author of several academic papers.

Wan Khairuzzaman is a professor of management at UTM. He is currently the dean of International Business School (IBS) in Universiti Teknologi Malaysia (UTM). He is also supervising students for their thesis (Master's and PhD degrees), panel for thesis presentations and administrative positions in numerous committees at university and faculty levels.

Amin Vakilbashi is a senior lecturer of management at International Business School (IBS) in Universiti Teknologi Malaysia (UTM). His research interests include leadership, global leadership and organizational culture. He is the author and co-author of several academic papers. 